\title{
Contributions of the Integral Hypothesis to the Confrontation of the Severity of Dengue: A Brief Opinion
}

\author{
Garcia LS* \\ University of Medical Sciences of Holguin, Cuba \\ *Corresponding author: Lourdes Serrano Garcia, University of Medical Sciences of Holguin, Cuba
}

\section{ARTICLE INFO}

Received: 慧 October 04, 2021

Published: October 19, 2021

Citation: Garcia LS. Contributions of the Integral Hypothesis to the Confrontation of the Severity of Dengue: A Brief Opinion. Biomed J Sci \& Tech Res 39(3)-2021. BJSTR. MS.ID.006303.

Keywords: Medical Training; Severe Dengue; Teaching; Learning

\begin{abstract}
Dengue is currently considered the most important arbovirus in the world in terms of human morbidity and mortality. This ill is considered an immunopathogenic disease, the severe or fatal manifestations of which are Dengue Hemorrhagic Fever (DHF) and Dengue Shock Syndrome (DSS). In patients with DHF / DSS, the prognosis depends on the early and effective recognition of shock, which is why it is necessary to have adequate surveillance of them. However, on numerous occasions some young medical students tend to express like a personal concern their ignorance about how to act to prevent death. Some hypotheses have been put forward to explain the serious condition, however, the author of this research agree that the Integral Hypothesis proposed by Kouri P. et al., is the most complete by pointing out, like no other, dengue like a multifactorial immunopathological phenomenon. Hence, it is proposed the systematizing of this perspective to improve medical teaching in order to enrich the quality of sanitary services.
\end{abstract}

Abbreviations: DHF: Dengue Hemorrhagic Fever; DSS: Dengue Shock Syndrome; DF: Dengue Fever

\section{Opinion}

Dengue is currently considered the most important arbovirus in the world in terms of human morbidity and mortality [1]. The number of cases notified by the World Health Organization (WHO) has increased eightfold in the last two decades, from 505.430 in 2000 to more than 2.4 million in 2019 [2]. The consideration of dengue as an immunopathogenic disease, where the immune response and not the virus per se is responsible for the clinical picture, emerges like a valuable perspective that offers helpful information for its successful confrontation [1]. As it is known, Dengue Hemorrhagic Fever (DHF) and Dengue Shock Syndrome (DSS) are the severe or fatal manifestations of Dengue Fever (DF), however, in numerous occasions some young students of Medical career expose as a personal concern their ignorance about how to act to prevent death [3]. In patients with DHF/DSS, the prognosis depends on the early and effective recognition of shock that is why it is necessary to have an adequate surveillance of them, especially during the critical period, framed in the transition from the febrile to the afebrile phase, which generally occurs after the third day of the onset of the clinical presentation [4]. In this sense, it is recognized that timely and adequate medical assistance reduces mortality rates below $1 \%$ [3]. The above makes us reflect on how much still needs to be learned and how much remains to be taught regarding this subject [4].

The relevant role of the immune response in the pathophysiology of severe forms of this illness dates from the late 1980s, but despite having tried to explain exactly, it still remains without a clear explanation. In fact, some valuable hypotheses have been raised to elucidate the serious condition [1], nevertheless, the author agree with other researchers [5] that the Integral Hypothesis proposed by Kouri P, et al. [6], is the most complete when pointing out like 
no one other, dengue like a multifactorial immunopathological phenomenon. It was in 1987 that Kouri P carried out a research in Cuban territory and came to the conclusion that a better understanding of the worsening of dengue would be possible through the analysis of various factors, to say: factors of individual risks (presence of anti-dengue antibodies, age, sex, race, chronic disease carrier), epidemiological (vector and interval between infections) and factors related to the virus (serotype and virulence of the strain) that, as a consequence of its interaction lead the development of severity [6]. In this way, it is considered paradoxical that, despite the usefulness of these postulates, the researches related to its verification have been so limited. In addition, not only the scientific value of its particular content is distinguished in this hypothesis, but also the advocacy of the ethical, the environmental and the sociocultural with a more dynamic vision of the still enigmatic health-disease process.

Hence, the author commit with this viewpoint, since it exclusively conceives key elements that contribute to solving the problem raised, which from other prospects are often undervalued. It would be regrettable not to exploit the knowledge that this hypothesis contains and also the wide range of representational elements that it considers. Additionally, it must be emphasized that considerations emanated from this view contribute with the most complete and holistic professional training of sanitary personnel, by providing a conception in which, not only is the health sector positioned like the protagonist of the pertinent confrontation of the problem, but also conceives the population involved like a key element or active subjects with the right to make decisions regarding their reality. The need to address the shortcomings revealed in higher medical education regarding to the teachinglearning of contents concerning to confronting the evolution of dengue towards its fatal forms, is imminent, and guides this author to discover in the mentioned hypothesis a particular form of the application of the scientific method in the medical profession. It is offering an invitation to reflecting about the possible solutions that may arise as result of a deep analysis of this point of view in order to diminish the uncertainty of students about the knowledge required in this area and thus to enrich the quality of health services. It is known that the problem associated with the way in which optimal decisions are made and should be made, has been treated in numerous studies.
Among the elements of the analysis of said investigations, it is highlighted that: individuals have a limited capacity for processing and analyzing information, as well as knowledge, which allow making the most rational decisions [7]. This process is not only permeated by each individual's own mental model and social relationships, the quality of the professional teachingeducational process pursued by the subject is also considered a determining factor for the choice of the final decision. Based in previous, actually is evidenced a general acceptance to introduce activities that propitiate the clinical reasoning from the first stages of the formation of the doctors [8]. Finally, it is considered that the Integral Hypothesis offers a procedure that develops the incipient capabilities of clinical reasoning and illustrates the applicability of the contents referred in this paper.

\section{Acknowledgment}

Author (Lourdes Serrano) offers infinite acknowledges to the Financial and Editorial offices of the Biomedical Journal of Scientific \& Technical Research (BJSTR) for the complete financing of this paper.

\section{Competing Interest}

The author has declared that no competing interest exists.

\section{References}

1. Serrano L, García L (2020) Hypotheses that help to explain the immunopathogenic phenomenon of dengue. Correo Científico Médico 24(1): 4 .

2. (2019) World Health Organization. Dengue and severe dengue.

3. Serrano L, Serrano L, Rodríguez AJ (2020) Does the HIV survive out of the human host? Rev Panorama. Cuba y Salud 15(2): 65-66.

4. Serrano L, Serrano L (2019) Molecular and physiological events moduled by Dengue. Correo Científico Médico 23(1): 265-269.

5. Sierra Vásquez B, García Menéndez G, Pérez Díaz AB (2016) Innate immune system dengue virus infection. In: Sierra Vásquez B, García Menéndez G, Pérez Díaz AB (Eds.)., 2016: 317-332.

6. Kourí GP, Guzmán MG, Bravo JR (1987) Why dengue haemorrhagic fever in Cuba? An integral analysis. Transactions of The Royal Society of Tropical Medicine and Hygiene 81(5): 821-823.

7. Serrano L, Serrano L, Rodríguez AJ (2020) New perspective for the teaching-learning of the microbiological diagnostic investigations in Medical career. Rev Panorama Cuba y Salud 15(3): 108-109.

8. Vicedo A (2021) Basic sciences from a clinical case approach: objectives always tarjeted. Educac Med Sup 35(3): e2853. 
ISSN: 2574-1241

DOI: 10.26717/BJSTR.2021.39.006303

Garcia LS. Biomed J Sci \& Tech Res

(C) This work is licensed under Creative BY Commons Attribution 4.0 License

Submission Link: https://biomedres.us/submit-manuscript.php

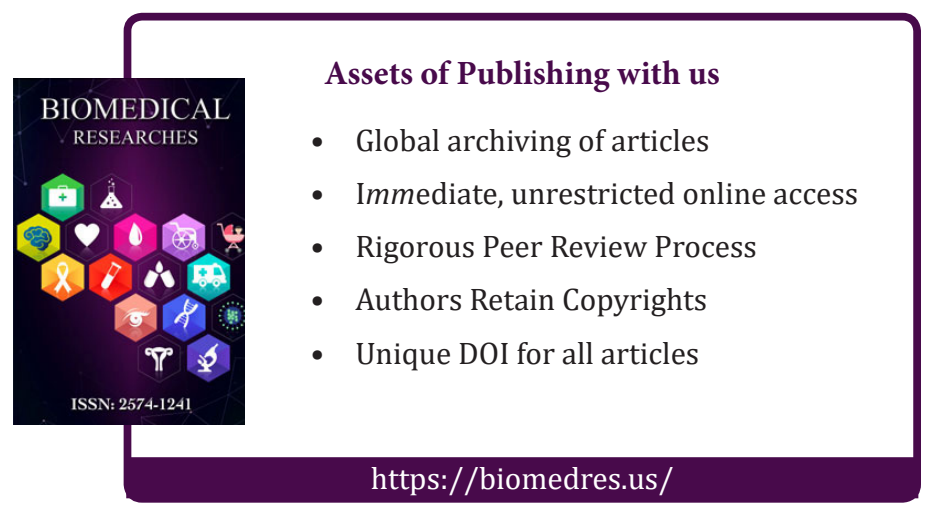

